\title{
EVALUATION OF NAA LABORATORY RESULTS IN INTER-COMPARISON ON DETERMINATION OF TRACE ELEMENTS IN FOOD AND ENVIRONMENTAL SAMPLES
}

\author{
Diah Dwiana Lestiani, Syukria Kurniawati and Natalia Adventini \\ Nuclear Technology Center for Materials and Radiometry - PTNBR, National Nuclear Energy Agency (BATAN) \\ JIn. Tamansari 71, Bandung - Indonesia, Telp:+62-22-250-3997, Fax:+62-22-250-4081, \\ e-mail: diahdwi@batan.go.id
}

Recived 13 January 2012, received in revised form 23 February 2012, accepted 6 March 2012

\begin{abstract}
Inter-comparison program is a good tool for improving quality and to enhance the accuracy and precision of the analytical techniques. By participating in this program, laboratories could demonstrate their capability and ensuring the quality of analysis results generated by analytical laboratories. The Neutron Activation Analysis (NAA) laboratory at National Nuclear Energy Agency of Indonesia (BATAN), Nuclear Technology Center for Materials and Radiometry-PTNBR laboratory participated in inter-comparison tests organized by NAA working group. Inter-comparison BATAN 2009 was the third inter-laboratory analysis test within that project. The participating laboratories were asked to analyze for trace elements using neutron activation analysis as the primary technique. Three materials were distributed to the participants representing foodstuff, and environmental material samples. Samples were irradiated in rabbit facility of G.A. Siwabessy reactor with neutron flux $\sim 10^{13}$ $n . \mathrm{cm}^{-2} . \mathrm{s}^{-1}$, and counted with HPGe detector of gamma spectrometry. Several trace elements in these samples were detected. The accuracy and precision evaluation based on International Atomic Energy Agency (IAEA) criteria was applied. In this paper the PTNBR NAA laboratory results is evaluated.
\end{abstract}

Keywords: inter-comparison, neutron activation analysis, trace elements, foodstuff, environmental samples, NAA laboratory

\section{INTRODUCTION}

$T$ he implementation of quality assurance to routine analytical laboratory activity is growing necessity in line with the global market demand to ensure that the credibility and confidentiality in laboratory results. Total of all lab activities should apply the quality system based on the standard that are undertaken to guarantee the accurate and reliable results. Inter-comparison programs are considered by laboratories as good tool for improving quality and enhancing the accuracy and precision of the analytical techniques. Inter-comparisons enable laboratories to demonstrate their capability and ensuring the quality of analysis results generated by analytical laboratories. It proves to others that the laboratories are proficient in their activities and guarantee their quality. Therefore, participation in inter-comparison is an important external quality assurance tool in conforming to ISO/IEC 1705 General requirements for the competence of testing and calibration laboratories ${ }^{(1)}$. Global market demands also drive this kind of needs, and it makes participation in inter-comparison or proficiency test is a mandatory requested by accreditation bodies or authorities.

The Neutron Activation Analysis laboratory in Nuclear Technology Center for Materials and Radiometry - PTNBR NAA laboratory is one of the nuclear analytical techniques group at National Nuclear Energy Agency of Indonesia (BATAN), mostly dedicated to the development of neutron activation analysis applications for various field of research particularly the environmental and nutritional studies. It also performs services for other institutions, laboratories and private customers. Since May 2006, PTNBR NAA lab has been accredited by National Accreditation Body (KAN) for implementing quality system based on ISO/IEC 17025:2005 and reaccredited in March 2011. The fact that nuclear analytical techniques are specific and only limited laboratory implies these techniques; several efforts are needed to be carried out to maintain the accreditation status. Due to 
the limitation of KAN to facilitate the inter-comparison study of NAA scope, NAA working group in BATAN has initiated to organize inter-comparison or proficiency test.

PTNBR NAA laboratory participated in inter-comparison BATAN 2009 which was the third interlaboratory analysis test within the project. The laboratories were asked to analyze for ten trace elements in each samples using neutron activation analysis as the primary technique ${ }^{(2)}$. In this paper, the PTNBR NAA laboratory result is presented to evaluate the performance, ensuring the quality and improving the capability of laboratory.

\section{METHODOLOGY}

\section{Sample Preparation}

Three materials were distributed to the participants representing foodstuffs and environmental material samples. Sample 1 and 2 were foodstuffs samples, and sample 3 was environmental samples. Samples were dried in oven to a constant mass before weighing. Triplicate $25 \mathrm{mg}$ portions were prepared for determination of short-lived, medium and long lived Instrumental Neutron Activation Analysis (INAA). The masses of each sample were recorded to $\pm 0.01 \mathrm{mg}$ using a five digits micro balance. Synthetic standard solutions were prepared from metals or compounds of known purity solution. For validation and to assess the accuracy of the analysis, National Institute Standards and Technology standard reference materials NIST SRM 1567a Wheat Flour, NIST SRM 1568a Rice Flour and NIST SRM 2711 Montana Soil were also analyzed. Each sample, each SRM and each standard were encapsulated in heat-sealed polyethylene vials prior to neutron irradiation.

\section{NAA Procedures}

INAA for products of neutron capture with short half-lives was used to determine $\mathrm{Al}, \mathrm{Ca}, \mathrm{Mg}, \mathrm{Mn}$, and $\mathrm{V}$, medium half-lives was used to determine $\mathrm{As}, \mathrm{K}$ and $\mathrm{Na}$, while for long lived products was used to determine $\mathrm{Co}$, $\mathrm{Cr}$, Fe, Se and $\mathrm{Zn}{ }^{(3,4)}$. Samples were irradiated in rabbit system facility of G.A Siwabessy Serpong reactor of 15 MW with neutron flux $\sim 10^{13} \mathrm{n} . \mathrm{cm}^{-2}$. $\mathrm{s}^{-1}$. For determination of short lived nuclides, each sample was irradiated for 5 minutes together with synthetic standards and NIST SRM, and then counted with HPGe detector of gamma spectrometry. The short-lived assays were performed after decay times of 5-15 min. For INAA determination of medium and longer-lived nuclides, samples, standards, control samples and NIST SRMs were placed into polyethylene irradiation containers and irradiated for 15 minutes and 2 hours respectively. Determination of medium-lived nuclides were performed after approximately 12 hours, while for long-lived nuclides determination were performed after approximately one-two months of decay, with each sample, SRMs or element standard were counted by gamma-ray germanium spectrometer with resolution $1.88 \mathrm{keV}$ in $1332 \mathrm{keV}{ }^{60} \mathrm{Co}$, peak to Compton ratio 42 and relative efficiency of $12 \%$.

The sample and standard were irradiated simultaneously and measured under the same condition. Therefore, using the relative method, elemental concentrations were calculated by comparison of the measured activity between the sampel and standard ${ }^{(3,4)}$.

\section{RESULT AND DISCUSSION}

\section{Method Validation}

The analysis results of NIST SRM 1567a Wheat Flour, NIST SRM 1568a Rice Flour and NIST SRM 2711 Montana Soil are shown in Figure 1, Figure 2 and Figure 3. The results showed a good agreement with the certificate value.

\section{Laboratory Results}

The analysis results of sample 1,2 and 3 that reported by PTNBR NAA laboratory to the intercomparison organizer are given in Table 1. The table gives the concentration of each requested element which the value was the average concentration of 2-4 times measurements, with its associated uncertainty. The uncertainty was mainly derived from the uncertainty in counting $(2 \sigma)$. 
Evaluation of NAA Laboratory Results In Inter-Comparison on Determination of Trace Elements In Food And Environmental Samples (Diah Dwiana Lestiani., et al)

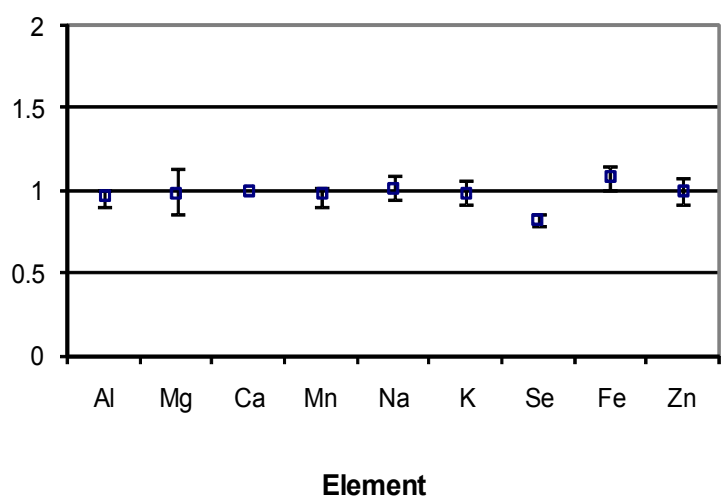

Figure 1. Method validation by analysis of SRM NIST 1567a Wheat Flour

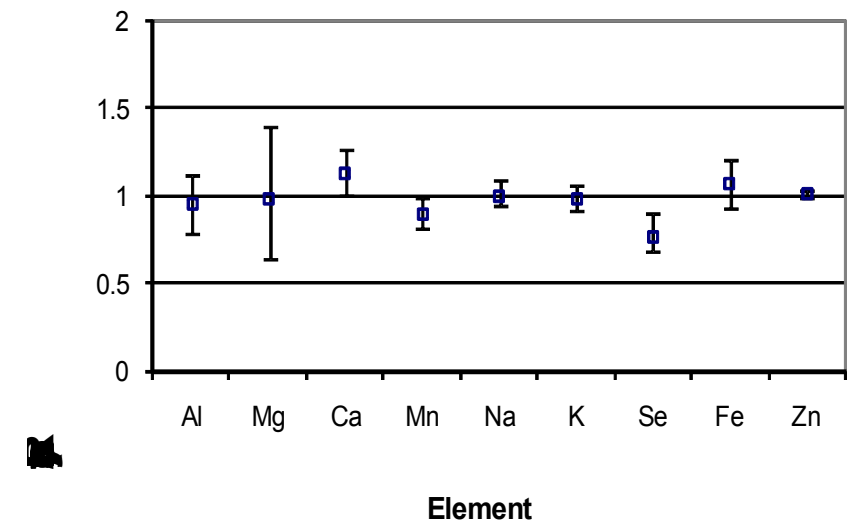

Figure 2. Method validation by analysis of SRM NIST 1568a Rice Flour

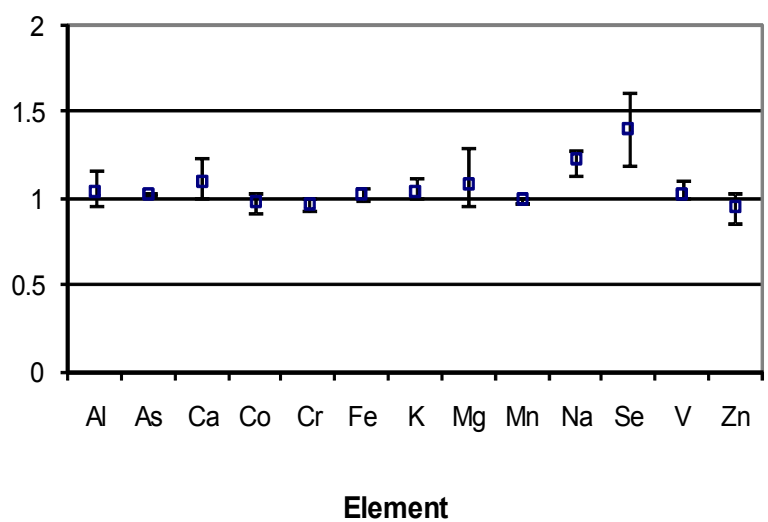

Figure 3. Method validation by analysis of SRM NIST 2711 Montana Soil

\section{Evaluation}

Performance evaluation criteria for trueness and precision are assigned the status "Acceptable" or "Not Acceptable" which are referred to International Atomic Energy Agency (IAEA) proficiency test statistical procedure ${ }^{(5)}$. Statistical analysis was applied including relative bias, ratio, $\mu$-test, accuracy and precision. Each parameter was calculated according to the following equation: 


$$
\begin{aligned}
& \text { relative bias }=\frac{\text { Value }_{\text {analyst }}-\text { Value }_{\text {true }}}{\text { Value }_{\text {true }}} \times 100 \% \\
& \text { ratio }=\frac{\text { Value }_{\text {analyst }}}{\text { Value }_{\text {true }}} \\
& \mu_{\text {test }}=\frac{\mid \text { Value }_{\text {true }}-\text { Value }_{\text {analyst }} \mid}{\sqrt{\text { unc }_{\text {true }}^{2}+\text { unc }_{\text {analyst }}^{2}}}
\end{aligned}
$$

which unc (uncertainty of reported value). For the $\mu$-test, the inter-comparison organizer set the limit of value of $\mu$-test parameter value to 2.58 for a level which means there is no significant different between the reported value and the true/certificate value $(\mu<2.58){ }^{(6)}$. The inter-comparison results were evaluated against the acceptance criteria for accuracy and precision, and assigned the status accordingly.

Accuracy result is assigned "acceptable" status if $A \leq B$

$$
\begin{aligned}
& A=\mid \text { Value }_{\text {trus / certificate }}-\text { Value }_{\text {analyst }} \mid \\
& B=1,95 \times \sqrt{u_{\text {unc }}^{\text {true / certificate }}+u_{\text {analyst }}^{2}}
\end{aligned}
$$

Precision result is assigned "acceptable" status if $\mathrm{C} \leq \mathrm{D}$

$$
\begin{aligned}
& C=\sqrt{\left[\left(\frac{\text { unc }_{\text {true }}}{\text { Value }_{\text {true }}}\right)^{2}+\left(\frac{\text { unc }_{\text {analyst }}}{\text { value }_{\text {analyst }}}\right)^{2}\right]} \times 100 \% \\
& D=\sqrt{\left[\left(\frac{\text { unc }_{\text {true }}}{\text { nilai }_{\text {true }}}\right)^{2}+\left(\sigma_{H}\right)^{2}\right]} \times 100 \%
\end{aligned}
$$

which $\sigma_{H}=0,02 \times c^{0,8495}$ and $c$ is the concentration of true value. A result must receive "acceptable" status in both criteria to be assigned the final status of "acceptable". Obviously, if a result has obtained "not acceptable" for both accuracy and precision, then the final score will be assigned as "not acceptable".

Table 1. PTNBR NAA Laboratory analysis results

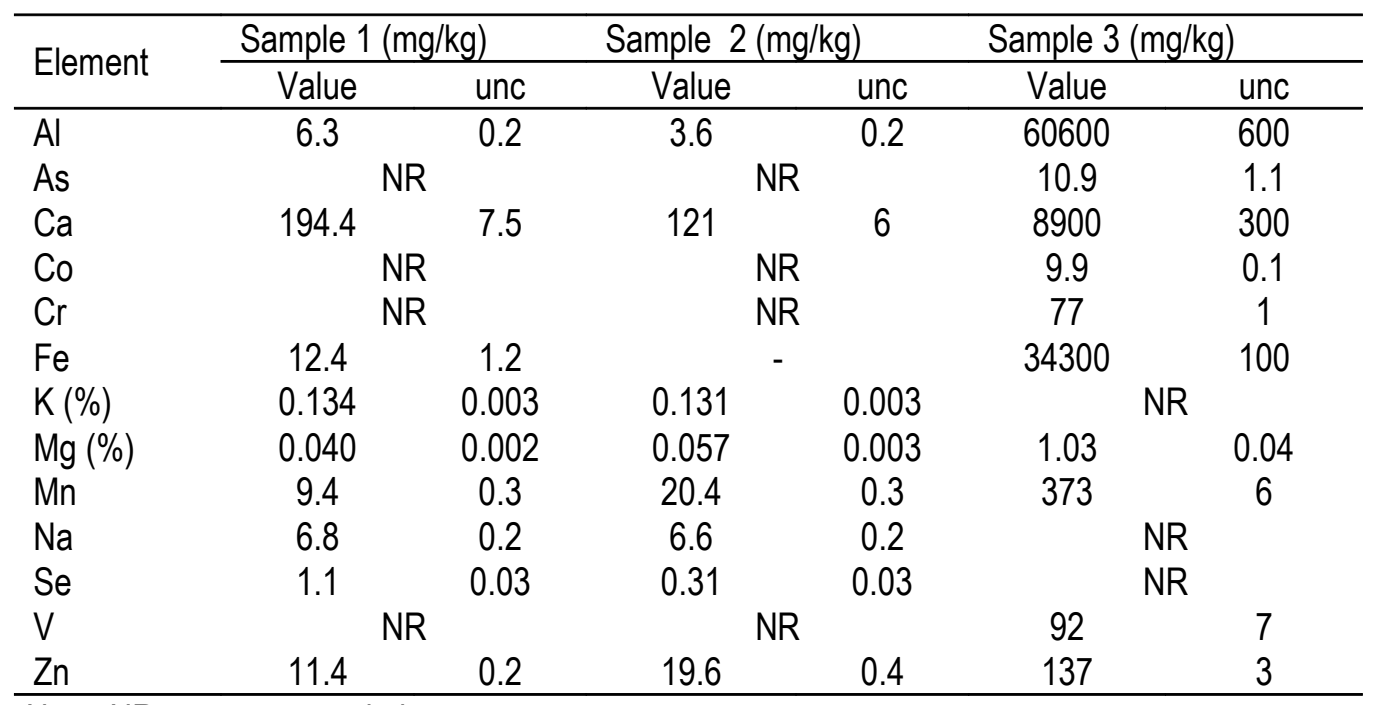

Note: NR : not requested element 
Evaluation of NAA Laboratory Results In Inter-Comparison on Determination of Trace Elements In Food And Environmental Samples (Diah Dwiana Lestiani., et al)

Table 2. Comparison reported value to certificate value

\begin{tabular}{|c|c|c|c|c|c|c|c|}
\hline \multirow{2}{*}{ Element } & \multicolumn{2}{|c|}{$\begin{array}{l}\text { True/certificate } \\
\text { value }(\mathrm{mg} / \mathrm{kg})\end{array}$} & \multicolumn{2}{|c|}{$\begin{array}{l}\text { Reported value by } \\
\text { analyst (mg/kg) }\end{array}$} & \multirow{2}{*}{$\begin{array}{l}\text { Relative } \\
\text { Bias \% }\end{array}$} & \multirow{2}{*}{$\mu$-test } & \multirow{2}{*}{ Ratio } \\
\hline & Value & unc & Value & unc & & & \\
\hline \multicolumn{8}{|l|}{ Sample 1} \\
\hline $\mathrm{Al}$ & 5.7 & 1.3 & 6.3 & 0.2 & 10.7 & 0.47 & 1.11 \\
\hline $\mathrm{Ca}(\%)$ & 0.019 & 0.0004 & 0.0194 & 0.0008 & 1.8 & 0.40 & 1.02 \\
\hline $\mathrm{Mg}(\%)$ & 0.040 & 0.002 & 0.040 & 0.002 & 1.2 & 0.16 & 1.01 \\
\hline $\mathrm{Mn}$ & 9.4 & 0.9 & 9.4 & 0.3 & 0.0 & 0.00 & 1.00 \\
\hline $\mathrm{Na}$ & 6.1 & 0.8 & 6.8 & 0.2 & 11.5 & 0.85 & 1.11 \\
\hline K (\%) & 0.133 & 0.003 & 0.134 & 0.003 & 0.8 & 0.24 & 1.01 \\
\hline $\mathrm{Fe}$ & 14.1 & 0.5 & 12.4 & 1.2 & 11.9 & 1.31 & 0.88 \\
\hline Se & 1.1 & 0.2 & 1.10 & 0.03 & 0.0 & 0.00 & 1.00 \\
\hline $\mathrm{Zn}$ & 11.6 & 0.4 & 11.39 & 0.24 & 1.8 & 0.45 & 0.98 \\
\hline
\end{tabular}

Sample 2

$\begin{array}{lccccccc}\mathrm{Al} & 4.4 & 1.0 & 3.6 & 0.2 & 18.2 & 1.19 & 0.82 \\ \mathrm{Ca}(\%) & 0.011 & 0.0006 & 0.0121 & 0.0006 & 2.8 & 0.40 & 1.03 \\ \mathrm{Mg}(\%) & 0.056 & 0.002 & 0.057 & 0.003 & 1.0 & 0.16 & 1.01 \\ \mathrm{Mn} & 20.0 & 1.6 & 20.4 & 0.3 & 2.0 & 0.25 & 1.02 \\ \mathrm{Na} & 6.6 & 0.8 & 6.6 & 0.2 & 0.5 & 0.04 & 1.00 \\ \mathrm{~K}(\%) & 0.128 & 0.0008 & 0.1310 & 0.0030 & 2.3 & 0.97 & 1.02 \\ \mathrm{Se} & 0.38 & 0.04 & 0.31 & 0.03 & 18.4 & 1.40 & 0.82 \\ \mathrm{Zn} & 19.4 & 0.5 & 19.6 & 0.4 & 1.0 & 0.31 & 0.99\end{array}$

Sample 3

\begin{tabular}{lccccccc}
$\mathrm{Al}(\%)$ & 6.25 & 0.02 & 6.06 & 0.06 & 3.0 & 0.91 & 0.97 \\
$\mathrm{As}$ & 11.6 & 1.3 & 10.9 & 1.1 & 6.1 & 0.42 & 0.94 \\
$\mathrm{Ca}(\%)$ & 0.83 & 0.03 & 0.89 & 0.03 & 7.2 & 1.41 & 1.07 \\
$\mathrm{Co}$ & 10.5 & 1.3 & 9.9 & 0.1 & 5.6 & 0.45 & 0.94 \\
$\mathrm{Cr}$ & 76 & 3 & 77 & 1 & 1.1 & 0.26 & 1.01 \\
$\mathrm{Fe}(\%)$ & 3.35 & 0.10 & 3.43 & 0.01 & 2.7 & 0.80 & 1.02 \\
$\mathrm{Mg}(\%)$ & 1.09 & 0.08 & 1.03 & 0.04 & 5.5 & 0.67 & 0.94 \\
$\mathrm{Mn}$ & 375 & 20 & 373 & 6 & 0.5 & 0.09 & 1.00 \\
$\mathrm{~V}$ & 94 & 1 & 92 & 7 & 1.9 & 0.27 & 0.98 \\
$\mathrm{Zn}$ & 138 & 6 & 137 & 3 & 0.6 & 0.12 & 0.99 \\
\hline
\end{tabular}


Table 3. Accuracy and precision criteria for assignment "acceptance"

\begin{tabular}{|c|c|c|c|c|c|c|c|}
\hline \multirow[b]{2}{*}{ Element } & \multicolumn{3}{|c|}{ Accuracy } & \multicolumn{3}{|c|}{ Precision } & \multirow[b]{2}{*}{$\begin{array}{c}\text { Final } \\
\text { assignment }\end{array}$} \\
\hline & A & B & $\begin{array}{l}\text { Status } \\
A \leq B\end{array}$ & C & $D$ & $\begin{array}{l}\text { Status } \\
C \leq D\end{array}$ & \\
\hline \multicolumn{8}{|l|}{ Sample 1} \\
\hline $\mathrm{Al}$ & 0.6 & 2.56 & OK & 23.0 & 25.8 & OK & Passed \\
\hline K & 0.001 & 0.008 & OK & 3.2 & 11.1 & OK & Passed \\
\hline $\mathrm{Mg}$ & 0.0005 & 0.0056 & OK & 7.2 & 13.9 & OK & Passed \\
\hline $\mathrm{Mn}$ & 0.00 & 1.85 & OK & 10.1 & 14.9 & OK & Passed \\
\hline $\mathrm{Na}$ & 0.70 & 1.61 & OK & 13.4 & 17.8 & OK & Passed \\
\hline $\mathrm{Ca}$ & 0.0003 & 0.0017 & OK & 4.4 & 14.6 & OK & Passed \\
\hline $\mathrm{Fe}$ & 1.7 & 2.5 & OK & 10.1 & 11.5 & OK & Passed \\
\hline $\mathrm{Se}$ & 0.00 & 0.39 & OK & 18.4 & 24.1 & OK & Passed \\
\hline $\mathrm{Zn}$ & 0.21 & 0.91 & OK & 4.0 & 11.6 & OK & Passed \\
\hline \multicolumn{8}{|l|}{ Sample 2} \\
\hline Al & 1.20 & 1.96 & OK & 22.9 & 26.4 & OK & Passed \\
\hline K & 0.003 & 0.006 & OK & 2.4 & 10.9 & OK & Passed \\
\hline $\mathrm{Mg}$ & 0.001 & 0.007 & OK & 6.5 & 12.8 & OK & Passed \\
\hline $\mathrm{Mn}$ & 0.40 & 3.17 & OK & 8.1 & 12.9 & OK & Passed \\
\hline $\mathrm{Na}$ & 0.03 & 1.59 & OK & 12.4 & 17.1 & OK & Passed \\
\hline $\mathrm{Ca}$ & 0.0003 & 0.0016 & OK & 7.0 & 16.3 & OK & Passed \\
\hline $\mathrm{Se}$ & 0.07 & 0.10 & OK & 14.3 & 21.8 & OK & Passed \\
\hline $\mathrm{Zn}$ & 0.20 & 1.27 & OK & 3.4 & 10.6 & OK & Passed \\
\hline \multicolumn{8}{|l|}{ Sample 3} \\
\hline $\mathrm{Al}$ & 0.19 & 0.41 & OK & 3.3 & 6.9 & OK & Passed \\
\hline Co & 0.59 & 2.54 & OK & 12.4 & 16.8 & OK & Passed \\
\hline $\mathrm{Cr}$ & 0.80 & 5.93 & OK & 4.0 & 9.2 & OK & Passed \\
\hline $\mathrm{Mn}$ & 1.80 & 40.89 & OK & 5.6 & 8.5 & OK & Passed \\
\hline V & 1.80 & 12.82 & OK & 7.1 & 8.2 & OK & Passed \\
\hline As & 0.71 & 3.33 & OK & 15.1 & 15.8 & OK & Passed \\
\hline $\mathrm{Ca}$ & 0.06 & 0.08 & OK & 4.9 & 8.9 & OK & Passed \\
\hline $\mathrm{Fe}$ & 0.08 & 0.20 & OK & 3.0 & 7.3 & OK & Passed \\
\hline $\mathrm{Mg}$ & 0.06 & 0.17 & OK & 8.3 & 10.8 & OK & Passed \\
\hline $\mathrm{Zn}$ & 0.80 & 13.35 & OK & 5.0 & 8.8 & OK & Passed \\
\hline
\end{tabular}

Statistical evaluation was reported by organizer in March 2010, which gives the results of laboratory and scoring by approaching the IAEA performance criteria. PTNBR NAA laboratory performance statistical results, relative bias, $\mu$-test and ratio of reported to true value are presented in Table 2 . The ratio obtained for sample 1 , 2 and 3 gave range from $0.82-1.11$. The relative bias for all elements was less than $15 \%$, except for $\mathrm{Al}$ and $\mathrm{Se}$ in sample $2(18 \%)$. This bias is still in the range of allowable bias (20-25\%) for concentration in ppm level (0.1-1 $\mathrm{ppm})^{(7)}$. Eventhough the $\mu$-test score for those elements are still less than 2.58 in acceptable level which means there is no significant different between the reported value and the true/certificate value.

Acceptance assignment by accuracy and precision are summarized in Table 3 as provided by the intercomparison organizers ${ }^{(2)}$. All of elements reported by PTNBR NAA laboratory in each samples have passed the "acceptance" criteria. It showed the capability of PTNBR NAA laboratory has good competency and capability in determination of trace elements in foodstuffs and environmental matrix samples using neutron activation analysis. 


\section{CONCLUSIONS}

PTNBR NAA laboratory has participated in inter-comparison program provided by NAA working group in BATAN. It is a good tool for improving quality and to enhance the accuracy and precision of the analytical techniques. The inter-comparison BATAN III/2009 evaluation results showed that all reported result by PTNBR NAA laboratory are in agreement with the true value of inter-comparison samples. This evaluation also showed that PTNBR NAA laboratory has demonstrated its capability and ensuring the quality of analysis results generated by laboratory. For the continuous improvement, PTNBR NAA laboratory should participate in wide range inter-comparison for application of NAA in analysis of sample's matrix to maintain and improve laboratory's capability.

\section{Acknowledgment}

Acknowledgment for NAA Indonesia Forum for organizing the inter-comparison and staff of Center of Multipurporse Reactor and Center of Technology for Nuclear Industry Materials for their assistance and support in this research.

\section{REFERENCES}

1. ANONYMOUS., General requirements for the competence of testing and calibration laboratories, ISO/IEC 17025:2005 (2005).

2. IMAN KUNTORO, MUHAYATUN SANTOSO and SAEFUL YUSUF. Report of intercomparison NAA laboratories BATAN III, (2009)

3. WILLIAM D EHMANN, DIANE E. VANCE, Radiochemistry and Nuclear Methods of Analysis Volume 116, John Wiley \& Sons Inc. New York, (1991).

4. ANONYMOUS., Sampling and Analytical Methodologies for Instrumental Neutron Activation Analysis of Airborne Particulate Matter. Training course series no. 4, Vienna, INTERNATIONAL ATOMIC ENERGY AGENCY -IAEA., (1992)

5. ANONYMOUS., Analytical Quality Control Services, Summary Report of the Proficiency Test for the IAEA Project RAS/2/020: Quality Assurance and Quality Control of Nuclear Analytical Techniques, Seibersdorf, Austria, INTERNATIONAL ATOMIC ENERGY AGENCY -IAEA., (2003)

6. ANONYMOUS., Worldwide Open Proficiency Test on the Determination of Radionuclides in Spinach, Soil and Water. IAEA Analytical Quality in Nuclear Applications Series No.8, Vienna, INTERNATIONAL ATOMIC ENERGY AGENCY -IAEA., (2007)

7. AOAC., Guidelines for Singles Laboratory Validation of Chemical Methods for Dietary Supplements and Botanicals. Available in http://www.aoac.org. Accesed on January 15, (2010). 